\title{
MULA KERJA ATRAKURIUM
}

\author{
${ }^{1}$ Mukian M \\ ${ }^{2}$ Tambajong $\mathrm{H}$ \\ ${ }^{3}$ Lalenoh D \\ ${ }^{1}$ Kandidat Skripsi Fakultas Kedokteran Universitas Sam Ratulangi \\ ${ }^{2}$ Bagian Anestesiologi dan Terapi Intensif \\ djio_mednet@rocketmail.com
}

Background: Endotracheal intubation is the act of entering an endotracheal tube into the trachea so that the airway and breathing easyly assisted and controlled. Muscle paralytic drug greatly assist the implementation of general anesthesia, to facilitate endotracheal intubation including members and relaxation of the muscles that facilitate the operation and control of ventilation. Atracurium is a type of non-depolarising muscle paralysis does not depend on kidney. Purpose: To determine the average atracurium work early. Methods: The study was conducted in the Prof. Kandou hospital, Manado by using simple random sampling. Patients undergoing elective surgery with general anesthesia and met the inclusion criteria were weighed taken premedication with midazolam $0.07 \mathrm{mg} / \mathrm{kg}$ bw iv, fentanyl 2 microg $/ \mathrm{kg}$ bw iv and propovol induction with $2 \mathrm{mg} / \mathrm{kg}$ bw iv after patients given atracurium $0,6 \mathrm{mg} / \mathrm{kg}$ bw iv. Examination conducted by using TOF-watch and measured with a stop watch. Results: Found 14 samples studies with 5 male and 9 female. Conclusion: Based on the research that has been conducted on 14 samples found that the average of atracurium work initial 14 samples was 197 seconds (3.29 minutes).Keywords: atracurium, onset of action.

Latar belakang:Intubasi endotrakeal adalah tindakan memasukkan pipa endotrakeal kedalam trakea sehingga jalan nafas bebas hambatan dan nafas mudah dibantu dan dikendalikan. Obat pelumpuh otot sangat membantu pelaksanaan anestetik umum, antara lain memudahkan intubasi endotrakeal serta memberi relaksasi otot sehingga mempermudah pembedahan dan ventilasi kendali.Atrakurium adalah jenis pelumpuh otot non depolarisasi yang tidak tergantung dengan fungsi ginjal.Tujuan: Untuk mengetahui rerata mula kerjaatrakurium.Metode: Penelitian ini mengambil tempat di RSUP Prof Kandou,Manadodengan menggunakan simple random sampling.Pasien yang akan menjalani bedah elektif dengan anestetik umum dan memenuhi kriteria inklusi ditimbang berat badan dan dilakukan premedikasi dengan midazolam $0,07 \mathrm{mg} / \mathrm{kg}$ bb iv, fentanyl $2 \mu \mathrm{g} / \mathrm{kg}$ bb iv dan di induksi dengan propovol $2 \mathrm{mg} / \mathrm{kg}$ bb iv setelah itu pasien diberikan atrakurium $0,6 \mathrm{mg} / \mathrm{kg}$ bb iv. Pemeriksaan dilakukan dengan menggunakan TOF-watch dan diukur dengan stop watch.Hasil: Ditemukan 14 sampel penelitian dengan laki-laki 5 orang dan perempuan 9 orang.Kesimpulan: Berdasarkan penelitian yang telah dilakukan terhadap 14 sampel ditemukan bahwa rerata mula kerja atrakurium pada 14 sampel yaitu 197 detik (3,29 menit).Kata kunci: atrakurium, mula kerja.

\section{PENDAHULUAN}

Intubasi endotrakeal adalah tindakan memasukkan pipa endotrakeal kedalam trakea sehingga jalan nafas bebas hambatan dan nafas mudah dibantu dan dikendalikan. Tujuan dilakukannya intubasi endotrakeal adalah untuk membersihkan jalan nafas agar tetap paten, mencegah aspirasi, serta mempermudah pemberian ventilasi dan oksigen bagi pasien operasi. ${ }^{1,2}$
Untuk memasukkan pipa endotrakeal kedalam trakea tentu saja pasien akan merasakan ketidaknyamanan dan akan melakukan tindakan perlawanan sehingga akan terjadi trauma. ${ }^{3,4}$ Obat pelumpuh otot sangat membantu pelaksanaan anestetik umum, antara lain memudahkan intubasi endotrakeal serta memberi relaksasi otot sehingga mempermudah pembedahan dan ventilasi kendali. $^{5}$ 
Banyak pelumpuh otot yang sangat tergantung dengan ekskresi ginjal untuk eliminasinya.Atrakurium adalah jenis pelumpuh otot non depolarisasi yang tidak tergantung dengan fungsi ginjal. Atrakurium dimetabolisme secara efektif sehingga farmakokinetiknya tidak bergantung pada fungsi ginjal dan hati. ${ }^{6}$ Atrakurium digunakan sebagai tambahan dalam anestetik umum, untuk memfasilitasi pemasangan intubasi endotrakeal dan untuk memberikan relaksasi otot skeletal selama pembedahan atau ventilasi mekanis. ${ }^{7}$

Atrakurium ditemukan oleh Stenlake dan sejawatnya pada pertengahan 1970, yang dirancang untuk menghasilkan relaksasi nondepolarisasi dan mengalami eliminasi Hoffmann. Dalam reaksi kimia ini, suatu siklus pengelompokkan nitrogen qartenary dibawah $\mathrm{PH}$ dan temperatur yang tinggi terlepas menjadi amine tersier. Obat ini pertama kali diperkenalkan dalam penggunaan klinis di Inggris oleh Payne dan Hughes pada tahun 1981 dan di Amerika serikat oleh Basta pada tahun $1982 .^{8}$

Walaupun obat pelumpuh otot bukan merupakan obat anestetik, tetapi obat ini sangat membantu pelaksanaan anestestik umum, antara lain memudahkan dan mengurangi cedera tindakan laringoskop dan intubasi trakea, serta memberi relaksasi otot yang dibutuhkan dalam pembedahan ventilasi. ${ }^{9}$

Penelitian ini bertujuan untuk mengetahui mula kerja atrakurium.

\section{Metode Penelitian}

Penelitian ini dilakukan pada 25 Nopember 2012 hingga 21 Januari 2013 di Instalasi Bedah Sentral (IBS) dan Ruang Operasi Cito Rumah SakitProf. Dr. R. D. Kandou. Penelitian dilakukan pada seluruh pasien yang akan menjalani operasi dengan anestetik umum dan pemasangan pipa trakea. Kriteria penerimaan antara lain laki-laki dan perempuan berumur 18 hingga 40 tahun dengan status fisik ASA I-II. Kriteria penolakan yaitu pasien yang memiliki status fisik ASA III-VI dan memiliki alergi terhadap atrakurium.

Pasien yang masuk kriteria penerimaan diukur berat badannya sebelum masuk kamar operasi. Kemudian pasien dilakukan premedikasi dengan midazolam 0,07 mg/kg BB IV dan fentanil $2 \mu \mathrm{g} / \mathrm{kg}$ BB IV saat di atas meja operasi. Setelah itu, elektroda ditempelkan di daerah pergelangan tangan kiri pasien. Elektroda negatif ditempel kira-kira $2 \mathrm{~cm}$ proksimal pergelangan tangan dia atas kulit tempat jalannya nervus ulnaris. Elektroda positif ditempelkan 2-3 cm proksimal dari elektroda negatif. Kerdua elektroda dihubungkan pada nerve stimulator (TOF-watch). Tempelkan transducer pada bagian volar jempol dengan plester dan pastikan agar kabel tidak terlalu tegang. Kemudian TOFwatch dihidupkan.

Pasien diinduksi dengan propovol $2 \mathrm{mg} / \mathrm{kg}$ BB IV. Setelah itu, pasien diperiksa refleks bulu matanya dan pastikan hasilnya negatif. Saat pasien tidak lagi memilki refleks bulu mata, tekan tombol TOF (train of four) pada TOF-watch.Atrakurium $\quad 0,6 \mathrm{mg} / \mathrm{kg} \quad \mathrm{BB}$ diberikan pada pasien melalui jalur intravena secara cepat. Selesai penyuntikan, tombol start pada stopwatch ditekan untuk memulai penghitungan waktu. Tombol stop pada stopwatch ditekan apabila angka yang ditunjukkan pada layar TOF-watch mencapai $0 \%$.

\section{Hasil penelitian}

Telah dilakukan penelitian terhadap pasien yang akan menjalani operasai elektif di RSUP Prof Kandou, Manado dari bulan November 2012 sampai dengan bulan januari 2013 dengan status ASA I-II dan memenuhi kriteria inklusi dan ekslusi yang telah diberikan atrakurium 0,6 $\mathrm{mg} / \mathrm{kgBB}$ IV didapatkan sebanyak 14 sampel. 
Tabel 2.Karakteristik individu

\begin{tabular}{lrrrrr}
\hline Variabel & N & Minimum & Maksimum & rerata & \multicolumn{1}{c}{$\begin{array}{c}\text { Simpang } \\
\text { baku }\end{array}$} \\
\hline Umur (tahun) & 14 & 21 & 40 & 32.43 & 7.542 \\
Berat badan (kg) & 14 & 44.3 & 95.0 & 60.071 & 12.7252 \\
Mula kerja (detik) & 14 & 77 & 332 & 197.21 & 80.646 \\
\hline
\end{tabular}

Tabel diatas menunjukkan kategori umur termuda 21 tahun, umur tertua 40 tahun, dengan rerata 32,43 tahun memiliki standar deviasi 7,542. Sedangkan untuk kategori berat badan terendah $44,3 \mathrm{~kg}$, berat badan terberat 95 $\mathrm{kg}$ dengan rerata $60 \mathrm{~kg}$ memiliki standar deviasi 12,7252. Sedangkan untuk kategori mula kerja terendah 77 detik, mula kerja terlama 332 detik dengan rerata 197,21 detik memiliki standar deviasi 80,646.

Tabel 3.Subyek penelitian

\begin{tabular}{lcc}
\hline Jenis Kelamin & Frekuensi & $\%$ \\
\hline Laki-laki & 5 & 35.7 \\
Perempuan & 9 & 64.3 \\
Total & 14 & 100.0 \\
\hline
\end{tabular}

Tabel diatas menunjukkan dari 14 sampel terdapat 5 laki-laki $(35,7 \%)$ dan terdapat 9 perempuan $(64,3 \%)$.

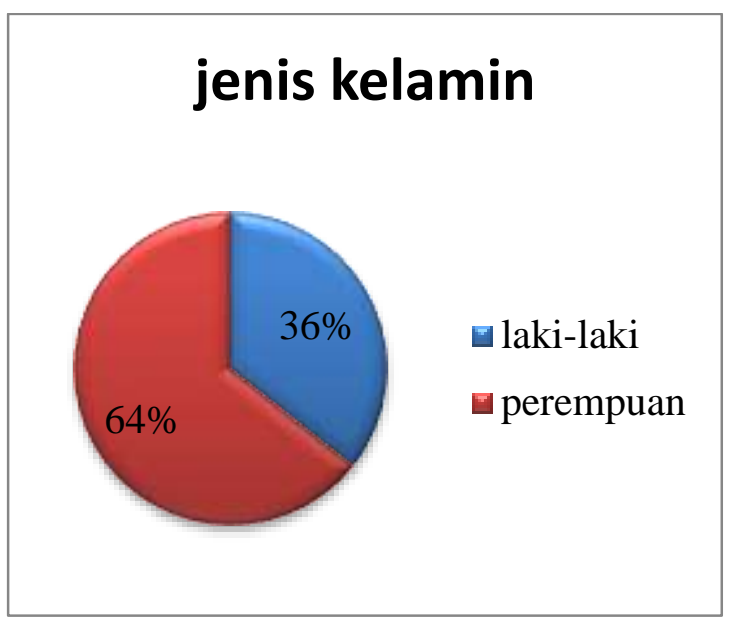

Gambar 3. Subyek penelitian

Kategori umur
Tabel 4.Kategori umur

\begin{tabular}{lcc}
\hline Kategori Umur & Frekuensi & $\%$ \\
\hline 18-25 tahun & 4 & 28.6 \\
26-33 Tahun & 3 & 21.4 \\
34-40 Tahun & 7 & 50.0 \\
Total & 14 & 100.0 \\
\hline
\end{tabular}

Tabel diatas menunjukkan dari 14 sampel ditemukan kategori umur 18-25 tahun terdapat 4 orang $(28,8 \%)$, kategori umur 26-33 tahun terdapat 3 orang (\%), kategori umur 34-40 tahun terdapat 7orang $(50 \%)$.

\section{kategori umur}

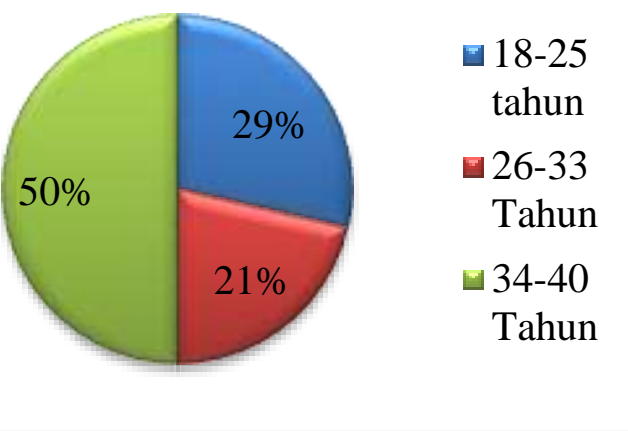

Gambar 4.Kategori umur.

Tabel 5.Kategori mula kerja

\begin{tabular}{lcc}
\hline Kategori Mula Kerja & $\begin{array}{c}\text { Frekuen } \\
\text { si }\end{array}$ & $\%$ \\
\hline 61-120 detik & 1 & 7.1 \\
121-180 detik & 6 & 42.9 \\
Diatas sama dengan 181 & 7 & 50.0 \\
Total & 14 & 100.0 \\
\hline
\end{tabular}


Dari tabel diatas menunjukkan dari total 14 sampel ditemukkan kategori mula kerja 61-120 detik sebanyak 1 orang (7,1\%), kategori mula kerja 121-180 detik sebanyak 6 orang (42\%), kategori mula kerja diatas sama dengan 181 sebanyak 7 orang $(50 \%)$.

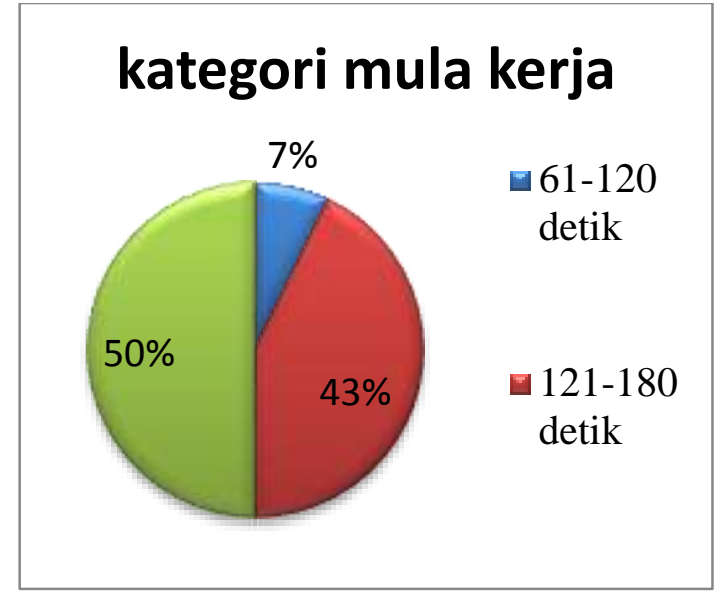

Gambar 5.Kategori mula kerja.

Uji beda mean mula kerja pada sampel laki-laki dan perempuan menggunakan uji

Tabel 6.Uji beda bearti mula kerja pada sampel laki-laki dan perempuan menggunakan uji t

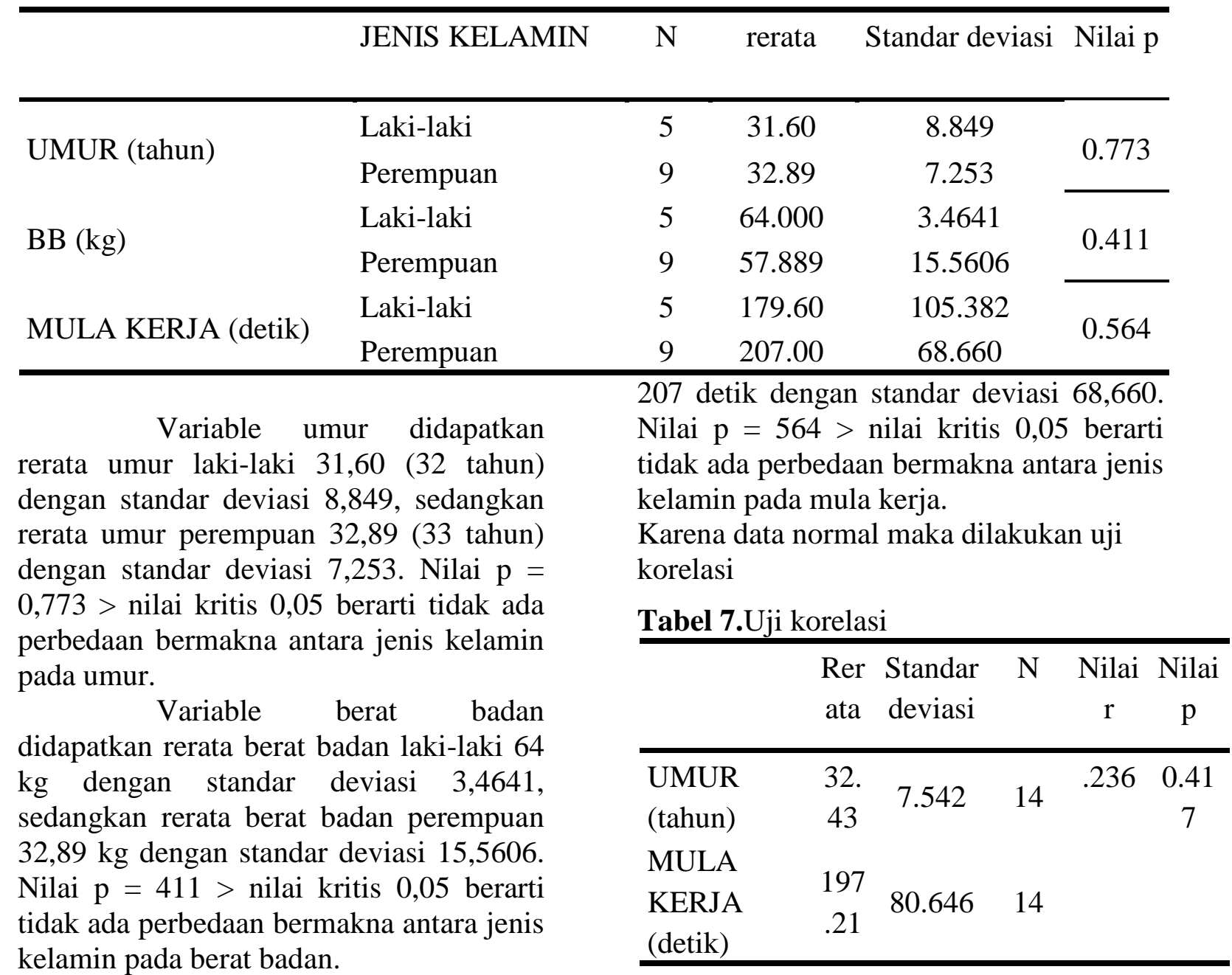

Nilai $\mathrm{p}=0,417>$ nilai kritis 0,05 berarti tidak ada hubungan signifikan antara umur dengan mula kerja. dengan standar deviasi 105,382, sedangkan rerata mula kerja perempuan
Variable mula kerja didapatkan rerata mula kerja laki-laki 179,60 detik 
Nilai $r=0,236$ artinya hubungan yang ada karena dibawah 0,25 atau mendekati nol. antara umur dan mula kerja sangat lemah

Hasil uji chi square

Tabel 8.kategori umur dan kategori mula kerja

\begin{tabular}{|c|c|c|c|c|c|c|}
\hline \multirow[b]{2}{*}{$\begin{array}{l}\text { kategori } \\
\text { Umur }\end{array}$} & \multicolumn{3}{|c|}{ Kategori Mula Kerja } & \multirow[b]{2}{*}{ Total } & \multirow[b]{2}{*}{ nilai $\mathrm{p}$} & \multirow[b]{2}{*}{ Signifikansi } \\
\hline & $\begin{array}{c}61-120 \\
\text { detik }\end{array}$ & $\begin{array}{c}\text { 121-180 } \\
\text { detik }\end{array}$ & $\begin{array}{c}\text { Diatas } \\
\text { sama } \\
\text { dengan } \\
181\end{array}$ & & & \\
\hline \multirow[t]{2}{*}{ 18-25 tahun } & 1 & 2 & 1 & 4 & \multirow{8}{*}{0,501} & \multirow{8}{*}{$\begin{array}{c}>0,05 \text { Tidak } \\
\text { signifikan }\end{array}$} \\
\hline & $25.0 \%$ & $50.0 \%$ & $25.0 \%$ & $100.0 \%$ & & \\
\hline 26-33 Tahun & 0 & 1 & 2 & 3 & & \\
\hline \multirow{3}{*}{ 34-40 Tahun } & $0.0 \%$ & $33.3 \%$ & $66.7 \%$ & $100.0 \%$ & & \\
\hline & 0 & 3 & 4 & 7 & & \\
\hline & $0.0 \%$ & $42.9 \%$ & $57.1 \%$ & $100.0 \%$ & & \\
\hline \multirow{2}{*}{ Total } & 1 & 6 & 7 & 14 & & \\
\hline & $7.1 \%$ & $42.9 \%$ & $50.0 \%$ & $100.0 \%$ & & \\
\hline
\end{tabular}

Tabel 4, menunjukkan sampel dengan kategori umur 18-25 tahun yang memiliki kategori mula kerja 60-120 detik ada 1 orang (25\%), sampel dengan kategori umur 18-25 tahun yang memiliki kategori mula kerja 121-180 detik ada 2 orang (50\%), sampel dengan kategori umur 18-25 tahun yang memiliki kategori mula kerja diatas sama dengan 181 detik ada 1 orang (25\%),

sampel dengan kategori umur 26-33 tahun tidak ada yang memiliki kategori mula kerja 60-120 detik , sampel dengan kategori umur 26-33 tahun yang memiliki kategori mula kerja 121-180 detik ada 1 orang (33,3\%), sampel dengan kategori umur 26-33 tahun yang memiliki kategori mula kerja diatas sama dengan 181 detik ada 2 orang $(66,7 \%)$,

sampel dengan kategori umur 34-40 tahun tidak ada yang memiliki kategori mula kerja 60-120 detik, sampel dengan kategori umur 34-40 tahun yang memiliki kategori mula kerja 121-180 detik ada 3 orang $(42,9 \%)$, sampel dengan kategori umur 34-40 tahun yang memiliki kategori mula kerja diatas sama dengan 181 detik ada 4 orang $(57,1 \%)$.

Dari uji chi-square didapatkan nilai $\mathrm{p}=0,501$ lebih dari nilai kritis 0,05 berarti dalam penelitian ini tidak terdapat hubungan signifikan antara variabel kategori umur dengan kategori mula kerja. 
Tabel 9.Kategori jenis kelamin dengan mula kerja

\begin{tabular}{|c|c|c|c|c|c|c|}
\hline \multirow[b]{2}{*}{$\begin{array}{c}\text { Jenis } \\
\text { Kelamin }\end{array}$} & \multicolumn{3}{|c|}{ Kategori Mula Kerja } & \multirow[b]{2}{*}{ Total } & \multirow[b]{2}{*}{ nilai $\mathrm{p}$} & \multirow[b]{2}{*}{ signifikansi } \\
\hline & $\begin{array}{c}\text { 61-120 } \\
\text { detik }\end{array}$ & $\begin{array}{c}121- \\
180 \\
\text { detik }\end{array}$ & $\begin{array}{c}\text { Diatas } \\
\text { sama } \\
\text { dengan } \\
181\end{array}$ & & & \\
\hline \multirow[t]{2}{*}{ Laki-laki } & 1 & 2 & 2 & 5 & \multirow{2}{*}{5} & \multirow{6}{*}{$\begin{array}{c}>0,05 \text { Tidak } \\
\text { signifikan }\end{array}$} \\
\hline & $20.0 \%$ & $40.0 \%$ & $40.0 \%$ & $100.0 \%$ & & \\
\hline \multirow[t]{2}{*}{ Perempuan } & 0 & 4 & 5 & 9 & \multirow{2}{*}{0,373} & \\
\hline & $0.0 \%$ & $44.4 \%$ & $55.6 \%$ & $100.0 \%$ & & \\
\hline \multirow{2}{*}{ total } & 1 & 6 & 7 & 14 & & \\
\hline & $7.1 \%$ & $42.9 \%$ & $50.0 \%$ & $100.0 \%$ & & \\
\hline
\end{tabular}

Tabel 5, menunjukkan sampel laki-laki yang memiliki kategori mula kerja $60-120$ detik ada 1 orang (20\%), sampel laki-laki yang memiliki kategori mula kerja 121-180 detik ada 2 orang (40\%), sampel laki-laki yang memiliki kategori mula kerja diatas sama dengan 181 detik ada 2 orang (40\%).

Sampel perempuan yang memiliki kategori mula kerja 60-120 detik ada 0 orang $(0 \%)$, sampel perempuan yang memiliki kategori mula 121-180 detik ada 4 orang $(44,4 \%)$, sampel perempuan yang memiliki kategori mula diatas sama dengan 181 detikt ada 5 orang $(56,6 \%)$.

\section{Pembahasan}

$\begin{array}{crr} & \text { Atrakurium } & \text { dimetabolisme } \\ \text { secara } & \text { ekstensif } & \text { sehingga }\end{array}$

farmakokinetiknya tidak bergantung pada fungsi ginjal dan hati. Dua proses terpisah berperan dalam metabolisme. Pertama, hidrolisis ester yang dikatalisis oleh esterase non spesifik, bukan oleh asetilkolinesterase atau pseudokolinesterase. Kedua melalui eliminasi Hoffmann dimana penghancuran kimia non enzimatik spontan terjadi pada ph dan suhu fisiologis. ${ }^{9}$

Pada hasil penelitian yang dilakukan di ruang operasi RSUP Prof. Kandou, Manado ditemukan 14 pasien yang diberikan $0,6 \mathrm{mg} / \mathrm{kg}$ bb IV dengan mula kerja tersingkat 77 detik (1 menit17 detik) dan terlama 332 detik (5 menit 32 detik) memiliki rerata mula kerja yaitu 3,29 menit atau 197 detik.

Dosis awal atrakurium yang dibutuhkan yaitu $0,5 \mathrm{mg} / \mathrm{kg}$ bb sampai 0,6 $\mathrm{mg} / \mathrm{kg}$ bb untuk mencapai blokade neuromuskular secara maksimum umumnya dalam waktu 3 sampai 5 menit. Untuk mendapatkan tindakan intubasi yang sesuai dapat dicapai dalam waktu 2 sampai 2,5 menit. $^{10}$

Walaupun obat pelumpuh otot bukan merupakan obat anestetik, tetapi obat ini sangat membantu pelaksanaan anestesi umum, antara lain memudahkan dan mengurangi cedera tindakan laringoskop dan intubasi trakea, serta memberi relaksasi otot yang dibutuhkan dalam pembedahan dan ventilasi. ${ }^{9}$

Manfaat obat ini di bidang anestesiologi antara lain untuk:

1. Memudahkan dan mengurangi cidera tindakan laringoskop dan intubasi trakea.

2. Membuat relaksasi selama tindakan pembedahan

3. Menghilangkan spasme laring dan refleks jalan napas atas selama anestesia 
4. Memudahkan pernapasan kendali selama anestesia

5. Mencegah terjadinya fasikulasi otot karena obat pelumpuh otot depolarisasi. ${ }^{9}$

Penelitian tentang mula kerja obat pelumpuh otot atrakurium pernah dilakukan juga oleh Mahbuba dan Rana Talib Al-Nafakh (2009) melakukan penelitian pada 25 kasus berbeda, jenis kelamin berbeda, dan berat badan berbeda kemudian diberikan atrakurium $0.6 \mathrm{mg} / \mathrm{kg}$ bb dan mula kerja yang didapatkan yaitu berkisar antara 1,5 menit sampai 2 menit pada pasien yang akan diintubasi untuk mengurangi efek fisiologis pada jantung. ${ }^{10}$ Menurut penelitian Jaafer Mahbbuba dan Rana Talib AL-Nafakh penggunaan atrakurium untuk kepentingan operasi sangat berguna karena atrakurium tidak membuat perubahan signifikan pada denyut nadi terutama pada pasien yang menderita jantung iskemik. ${ }^{10}$

Sebagai simpulan.Berdasarkan penelitian yang telah dilakukan terhadap 14 sampel pasien yang akan menjalani operasi di RSUP Prof Kandou, Manado ditemukan bahwa rerata mula kerja atrakurium pada 14 sampel yaitu 3,29 menit atau 197 detik. Oleh karena itu Atrakurium dapat diberikan karena selain sebagai obat mula kerja sedang, atrakurium juga tidak memiliki dampak yang signifikan terhadap denyut nadi, sehingga berguna bagi pasien dengan gejala jantung iskemik dan pasien yang berusia lanjut yang tidak dapat mentoleransi peningkatan denyut jantung.

\section{Ungkapan Terima Kasih}

Ucapan Terima Kasih ditujukan kepada dr. Lucky Kumaat, SpAn sebagai penguji 1, dr. Iddo Posangi, SpAn sebagai penguji 2 dan kepada semua pihak yang baik secara langsung maupun tidak langsung telah menumbuhkan ide pada penulis sehingga penulis dapat menyelesaikan artikel ini.

\section{DAFTAR PUSTAKA}

1. Ibrahim $\mathrm{H}$. Intubasi endotrakeal. [homepage on the Internet]. 2012 [cited 24 Oktober 2012]. Available from:http://id.scribd.com/doc/314370 05/Intubasi-Endotrakeal-by-HafizIbrahim

2. Morgan ED, Mikhail MS, Murray MJ. Clinical Anesthesiology. United states of America: 2006.

3. Intubasi endotrakeal. [homepage on the Internet]. c2012 [update 2012 November 1; cited 9 November 2012]. Available from: http://id.scribd.com/doc/31437005/Int ubasi-Endotrakeal-by-Hafiz-Ibrahim

4. Miller RD. Miller's anesthesia. Edisi 7. United states of America:Elsevier; 2009.

5. Bramantyo LV. Perbandingan perubahan gejala hemodinamika antara perkurisasi atrakurium0,05 $\mathrm{mg} / \mathrm{kg}$ BB dengan MgSO4 40\% 40 mg karena penggunaan suksinilkolin sebagai fasilitas intubasi. [homepageon the internet]. 2012[cited septembeer 30 2012]. Available from: http://eprints.undip.ac.id/7513/1/Li borius.

6. Atracurium. [homepage on the internet]. C2013 [update 2013 Januari 12; cited 2013 Januari 15]. Available from: http://id.scribd.com/doc/98084430/ Atracurium

7. Annisa. Atrakurium Besilate. [homepage on the internet]. 2012 [cited 2012 Sep 30]; Available fom:

http://ml.scribd.com/doc/68045186 /ATRAKURIUM

8. Atrakurium. [homepage on the internet]. Universitas Sumatera Utara; c2012 [update 2012 Nov 
24; cited 2012 Dec 13]. Available from:http://repository.usu.ac.id/bit stream/123456789/23705/4/Chapte r\%20II.pdf

9. Kurniawan A, Kusuma DI. Farmakologi Pelumpuh Otot. [homepage on the Internet]. 2013 [cited 2013 Januari 13]; Available from: http://id.scribd.com/doc/55353519/ 45630854-refrat-ndun

10. Mahbuba J, Al-Nafakh RT. The effect of atracurium on the pulse rate during rapid tracheal intubation. QMJ vol 5. 2009. 